\title{
The Scientific Method: Use It Correctly
}

\author{
J. T. Trevors
}

Published online: 27 November 2009

(C) Springer Science + Business Media B.V. 2009

Science is a systematic means of investigation that uses observations, experimentation and hypothesis testing in a wide range of subject disciplines. The correct experimental design, controls, reference standards, calibrations, standard operating procedures, statistical testing, random or systematic sampling, and blind studies are often necessary. In some research, initial observations or preliminary experiments lead to improved experimental designs and improved research and discoveries. Bias and subjectivity need to be removed so that the correct conclusions can be arrived at, and then further experimentation can be undertaken, if necessary. Science is not a belief system, but a method of investigation that is subjected to peer review with conclusions open to debates, and experimental results verified or dismissed by other researchers. The scientific method is not perfect, but it is the best method we currently have and has been used for centuries. Modern science is also highly dependent on complex technologies and instruments often coupled with advanced computing analysis. Scientists also require advanced degrees and education that take over a decade to complete. In reality, it takes a career lifetime to become a scientist.

J. T. Trevors $(\bowtie)$

Department of Environmental Biology,

School of Environmental Sciences,

University of Guelph,

Rm. 3220 Bovey Bldg.,

Guelph, ON N1G 2W1, Canada

e-mail: jtrevors@uoguelph.ca
So why do scientists submit and even publish articles that use the following descriptions in their research? It was assumed, in our opinion, we believe, I believe, I am speculating, we are speculating that. Science is not a belief system. You can believe in anything. These beliefs are products of the human imagination. You can believe the Earth is flat, the moon is composed of cheese, Martians' life on Mars, Greek and Roman gods exist, and there is eternal life. It is irrational to have such beliefs and there is no evidence for these beliefs. However, since humans have freewill and are often irrational, they often believe what they want to believe.

It is disturbing to see the use of beliefs, speculations, and opinions without supporting experimentation and data used in science journals. If I have done this, I plead guilty and apologize. You can believe anything, postulate anything, and hypothesize anything. This is not science. The hypothesis must be testable. The hypothesis should also be plausible — being reasonable and possible. Formulating a hypothesis that is not plausible, not scientifically testable, and proceeding with experiments anyway may not benefit humanity. A correctly formulated hypothesis is a valuable tool in science research. The imagination is not dulled and sometimes immense discoveries are forthcoming when one is diverted from the original experiments. Honesty, integrity, and lack of corruption are also needed for quality and correct science. Moreover, even scientists may have personal opinions that are beyond scientific verification. However, they should not be brought into the scientific arena and objective reality. 